\title{
О соотношении лексико-семантической категории предельности и глагольного вида
}

\author{
ЛАСЛО ЯСАИ \\ JÁSZAY László, ELTE BTK Orosz Nyelvi és Irodalmi Tanszék, H-1088 Budapest, Múzeum krt. 4/D. \\ E-mail: jaszay.laszlo@btk.elte.hu \\ (Received: 30 April 2015; accepted: 21 June 2015)
}

\begin{abstract}
This paper discusses the question what influence the category of limitativity has on the category of verbal aspect. From this point of view, the author focuses on the semantic types of aspectual pairs, and verbs of delimitative manner of action are analyzed in this respect as well. In conclusion, the author also touches upon the aspectual model of clusters which has received special emphasis in L. Janda's research.

Keywords: aspectology, Russian, aspectual pairs, types of limit, delimitative verbs
\end{abstract}

0. Вводные замечания. Нижеследующие мысли можно считать продолжением и дополнением статьи (ЯСАИ 2013), в центре которой стоял вопрос о границах видовой парности, - вопрос, рассматриваемый на разных этапах аспектологических исследований. В настоящей работе обсуждается проблема, связанная с влиянием категории предельности на категорию вида: именно в этом плане уделим внимание семантическим типам видовых пар, и также с этой точки зрения будем рассматривать статус глаголов делимитативного способа действия. В заключение коснемся по этому поводу и аспектуальной модели «видовых гнезд» (aspectual clusters), которые получили особый акцент в исследованиях Лоры Янды.

Опираясь на русскую аспектологическую традицию, но несколько упрощая вопрос о соотнесенности вида с предельностью, общую картину об отношениях, сложившихся между этими категориями, можно коротко представить следующим образом: СВ выражает всегда ограниченное пределом действие, а НСВ может выражать как предельное действие (в таком случае процесс направлен на достижение предела), так и непредельное действие, которое не направлено на предел и вообще не имеет отношения к пределу. Непредельное действие представлено двумя типами: а) оно может быть процессом с некоторой степенью активности действия (работать, бегать, плакать, бороться и др.) или б) состоянием. Последнее семантически подразделяется на разные подтипы - в частности, на обозначение положения в пространстве (висеть, лежать, стоять, сидеть), на ментальное состояние (знать, понимать, считать) и на эмоциональное состояние (любить, грустить, бояться). Данная лексико-семантическая классификация существенна в первую очередь с точки зрения видовой соотносительности: считается (и именно это отражается 
в лексикографической практике), что непредельные процессы и стативы не согласуются с идеей парного глагола $\mathrm{CB}$, тогда как от глаголов с предельной основой видовые пары образуются, точнее, они в таком случае должны быть образованы (см. сделать, написать, починить, похудеть, окрепнуть и т. п.). В современной аспектологии понятие предела обстоятельно и дифференцированно описано. По классификации А. В. Бондарко предел может быть внутренним (т. е. обусловленным характером действия в данном способе его представления) или внешним (обусловленным внешними, неглагольными факторами по отношению к действию), реальным (т. е. достигнутым) или потенциальным (направленным на достижение), эксплицитным или имплицитным (подразумеваемым в глаголе НСВ в определенных контекстных условиях), абсолютным (действие не может быть продолжено) или относительным (возможно продолжение действия) (об этом вопросе более подробно см. БОНДАРКО 1986: 15-17).

1. Уточняющие замечания. Не отрицая сущности сказанного, мы должны внести некоторые уточнения и сделать дополнительные замечания, так как несомненно наблюдаются и отклонения от представленных выше тенденций. С точки зрения коррелятивности обратим внимание на следующие два факта.

1) Вывод о том, что непредельность несовместима с видовой парностью, несостоятелен, так как существует ряд бесспорных (или общепризнанных) пар с непредельным значением НСВ: см. такие корреляты, как понимать, удивляться, выражсать, ощущать, чувствовать (при почувствовать), видеть (при увидеть), сльшиать (при усльшшать) и др. (см. вопрос о семантических типах видовых пар в пункте 2). Кроме того, заметим, что среди бесприставочных глаголов эмоционального состояния встречаются как парные, так и непарные глаголы. Ср. с этой точки зрения неодинаковое отношение имперфективов синонимического ряда «бояться» к возможности или невозможности перфективации: а) бояться и побояться составляют приблизительную пару (в которой СВ возможен лишь в некоторых контекстах), б) труситьструсить, дрейфить-сдрейфить, робеть-оробеть представляют собой пары, а в) имперфективы страшиться, трепетать, дрожать являются несоотносительнЫми (АПРЕСЯН 1997: 15-16).

2) В русском языке существуют и такие предельные глаголы НСВ, которые не актуализируют реализованного предела, поэтому они не имеют коррелята СВ. Так, синонимы вылогать и шантажировать выражают только «стремление» (направленность на предел), т. е. 'добиваться чего-л. шантажом', но не реализуют естественного результата с компонентом 'добиться' (нет перфектива *вымочь). С этой точки зрения следует коснуться и группы безличных глаголов, описывающих изменение в природе и, как следствие этого, способных обозначать и конец (естественный предел) этого изменения (ср. темнеет -стемнело, рассветает-рассвело, смеркается-смеркнулось, теплеет - потеплело, холодает - похолодало). В плане предельной семантики подобных глаголов обращает на себя внимание, что глаголы вечереть 
и светать не входят в формальную (морфологическую) пару, - в результате процесса вечереет или светает перфективное значение выражается по-другому: а) описательно: наступил вечер или б) с помощью пары рассветатьрассвести: светает-рассвело. В последнем случае наступление нового состояния может передаваться и коррелятом другой пары (посветлело), который, однако, в безличном употреблении выступает реже, чем в лично-двусоставной конструкции (ср. формулировки посветлело и посветлело небо). Значит, в обоих случаях отсутствие морфологически стандартной пары компенсируется функционально. По этому поводу отметим, что существующий в русском языке приставочный перфектив завечереть характеризуется как устаревшая или разговорная форма.

2. О семантических типах видовой парности. Видовые пары разнородны не только с морфологической точки зрения, но и семантически. Это значит, что в соотносительных глаголах между коррелятами НСB и СВ проявляются разного рода отношения, и именно это разнообразие служит основой их семантической классификации. Остановимся на важнейших типах видовой связи.

2.1. Основной тип. В соответствии с указанием во вводных замечаниях, сущность основного противопоставления определяется следующим образом: НСВ выражает предельный процесс (действие направлено на достижение предела) - СВ реализует достижение абсолютного предела (выражается естественный исход действия, результат процесса). В эту группу входят наиболее многочисленные пары - независимо от способа их образования - префиксации, суффиксации, расширения корня или супплетивизма: делать-сделать, строить-построить, решать-решить, убирать-убрать, ловить-поймать и др. Глаголы таких пар могут быть и непереходными: таять-растаять, вянуть-увянуть.

2.2. Пары с относительным пределом СВ. В таких парах действие НСВ характеризуется также «тендентивным пределом», однако корреляции данной группы отличаются от видовых пар основного типа тем, что здесь СВ ограничен не абсолютным, а относительным пределом. Это значит, что действие СВ в принципе может быть продолжено, что можно проиллюстрировать диагностическим контекстом: Цены уже очень повысились и продолжают повышаться (ГЛОвинскАЯ 1982: 9). Такому отношению соответствуют еще пары: сокращать(ся)-сократить(ся), увеличивать(ся)-увеличить(ся), усиливать (ся)-усилить (ся), слабеть-ослабеть, толстеть-потолстеть, худеть-похудеть и т. д. Возможность продолжения перфективного действия служит в аргументации М. Я. Гловинской причиной того, чтобы не считать наличие предела в глаголах СВ всеобщим явлением, характеризующим все перфективы (ср. ГловинскАя 1982: 9). Не желая идти вразрез с концепцией Бондарко о семантике предела (и принимая «относительный предел»как разновидность предела), мы считаем терминологически уместным применительно к таким парам название «градативы» (ПАдучевА 1996: 118-119) или «градационные пары» (ЗАлизняк-ШмелЕв 2000: 57). 
2.3. «Перфектные» видовые пары. Термин, введенный Е. В. Падучевой, указывает на обратное соотношение противопоставленных видов по сравнению с основным типом видовых пар: 'НСВ обозначает состояние (т. е. непредельное действие), наступившее как результат того, что имело место действие $\mathrm{CB}$ '. Таким образом, мы исходим из действия $\mathrm{CB}$, которым выделяется возникновение нового состояния, а НСВ при этом обозначает сохранение данного состояния: $я$ понял $=я$ понимаю. Другие употребительные пары, входящие в эту группу: увлечься-увлекаться, выразить-выражать, ощутить-ощущзать, почувствовать-чувствовать, увидеть-видеть, усльшать-сльшать и др.

2.4. Пары с реализованным пределом НСВ. В эту группу входят «глаголы достижения», выражающие событие. Имперфективы таких пар специфичны тем, что их семантическое содержание, подобно глаголам СВ, обязательно включает в себя и компонент достижения предела, и тем самым блокирует выражение процесса (значит, у них отсутствует актуально-длительное значение). Поэтому наиболее частотная позиция таких глаголов НСВ выражение многократности в сочетании со значением результата. Имеются в виду пары с основным значением 'достижение предела' - 'многократное достижение предела': достигнуть-достигать, найти-находить, потерятьтерять, прийти-приходить, принести-приносить, выучить-выучивать, вылечить-вылечивать, съесть-съедать, прочитать-прочитывать и др. Такие пары часто называют и «тривиальными» (ср. ПАдучевА 1996: 89, ЗАлизнякШМЕЛЕВ 2000: 56).

2.5. Пары типа мультипликатив-семельфактив. Здесь речь идет о противопоставлении НСВ и СВ как многоактного и одноактного действия: $n p b-$ гать-прыгнуть, толкать-толкнуть, дергать-дернуть, хлопать-хлопнуть, колоть-кольнуть, мигать-мигнуть, вздрагивать-вздрогнуть, вилять-вильнуть и т. п., а также и бросать-бросить, где перфектив не имеет суффикса -ну-. Эти два разных способа действия объединяются в видовую пару на основе их функциональных особенностей. 1) Большинство глаголов НСВ этой группы, помимо своей основной функции, т. е. выражения многоактного действия, в состоянии обозначать и один законченный акт в позиции настоящего исторического, соответствуя таким образом принятому в аспектологии критерию парности, сформулированному Ю. С. Масловым (см. МАслов 1948: 307). Так, во фразе Вор прыгает через забор (и убегает) выделенный глагол употребляется не как мультипликатив, а выступает как заместитель семельфактива прошедшего времени: Вор прыгнул через забор (и убежал). Кроме этой позиции возможны и другие контексты «с одноквантовой интерпретацией» глагола прыгать (см. ХРАКовский 1997: 236). 2) Если же указанная замена невозможна или сомнительна (ср. не точное соответствие форм виляет и вильнул или машет и махнул), функционирование таких глаголов в других контекстах все-таки приравнивает их к подлинным парам, ведь типично имперфективные контексты требуют мультипликатива (полный анализ данной ПроблеМЫ см. ХРАКОВСКИЙ 1997). 
3. Делимитативы и вопрос коррелятивности. Делимитативы - это глаголы СВ с временным ограничением длительности действия. Помимо общего значения СВ приставка по- указывает здесь на сравнительно краткий отрезок времени, см., например, глаголы поработать, поплакать, поиграть, потанцевать, посидеть и др. в сочетании с типичными для них лексическими показателями: часок, немножко, недолго, минут десять и т. п. Таким образом, делимитативы составляют группу уменьшительно-ограничительного способа действия. В лингвистическом плане по поводу делимитативов требуется, на наш взгляд, рассмотрение прежде всего следующих вопросов: 1) определение круга глаголов, от которых можно образовать делимитатив, 2) анализ изменения их основного (первичного) значения, 3) рассмотрение функционирования исходного глагола и делимитатива с точки зрения видовой соотносительности. В дальнейшем уделим внимание каждому из поставленных вопросов.

3.1. Глаголы, мотивирующие делимитативы. Делимитативы представляют среди способов действия один из самых продуктивных словообразовательных приемов, их сфера образования охватывает «глаголы деятельности» в широком смысле слова. На основе семантики бесприставочного мотивирующего глагола предлагаем различать следующие возможные случаи образования:

1) Когда деятельность выражается непереходным (следовательно, и непредельным) глаголом НСВ: побегать, погулять , покричать, поплавать, nоплакать, помолчать, попутешествовать, поработать.

2) Когда мотивирующий и собственно прямо-переходный глагол НСВ употребляется без объекта, т. е. в абсолютивной позиции (и, как следствие этого, в непредельном значении): почитать, пописать, поговорить, поиграть, попеть, потанцевать, покурить.

3) Когда объект при переходном глаголе формально налицо, но обозначается только ограниченность во времени действия, не касающаяся его результата (достижения абсолютного предела): почитать роман, полистать альбом, поварить яйца, поискать ключ. По этому поводу следует заметить, что делимитативное значение, как правило, не реализуется, если приставка по- является чистовидовой - построчть, попросить, поужинать и др. Правда, у некоторых глаголов в принципе это не исключено, см. глагол постиpamb, в значении 'выстирать', с одной стороны, и в делимитативном значении, с другой (Она некоторое время постирала, потом стала убирать).

4) Делимитатив образуется также от глаголов состояния при выражении положения в пространстве, если он употребляется с одушевленным субъектом: поспать, посидеть, полежать, поваляться, постоять. В этой связи подчеркнем, что одушевленный субъект предполагает действие, зависящее от своей воли, и это обстоятельство сближает данные глаголы состояния с глаголами деятельности (что проявляется и в том, что от них могут быть образованы делимитативы - ср. глаголы: Бабушка поработала, потом поспала немножко). Наблюдения над глаголами состояния подводят к такому выводу, 
что от подлинных стативов делимитатив не образуется, см. глаголы знать, значить, висеть и стоять с неодушевленным субъектом (ср. Там стоял дом при невозможности *постоял дом). В то же время надо заметить, что среди глаголов эмоционального состояния встречаются и такие, которые допускают образование делимитативного деривата, см. погрустить, попечалиться, повеселиться (каждый в значении 'некоторое время').

3.2. Изменения в значении делимитативов. Как уже указывалось выше, общее значение делимитативов заключается в обозначении ограниченного во времени действия, и при этом подразумевается сравнительно краткий промежуток времени. С другой стороны, однако, под влиянием внешних факторов нередко наблюдается изменение первичного значения глаголов данной группы. Й. Крекич еще в 1980-е годы обратил внимание на то, что делимитативы при эмоционально положительной оценке действия способны выражать и аугментативное значение, семантически пересекаясь с сатуративно-аугментативными глаголами (наработаться, наговориться и т. п.). В рассматриваемом здесь случае уменьшительно-временное значение переходит в увеличительно-количественную продолжительность. Возможность такого рода изменения объясняется субъективным восприятием времени: то, что приятно для нас, мы воспринимаем кратковременным и стремимся в своем сознании продлить (ср. КРекич 1989: 134, 139). Примеры, приведенные автором, показывают, что в коннотативном значении делимитативов аугментативная функция может реализоваться как при наличии показателя типа хорошо, здорово, обстоятельно (1), так и при отсутствии такой контекстной поддержки $(2,3)$, главное при этом, чтобы субъективная оценка действия была положительной. См. примеры: 1) Ему трудно было говорить. Но ему хотелось поговорить хорошо, обстоятельно (В. Шукшин: Как помирал старик); 2) Что ни спроси ее, она обо всем знает: поездила, поглядела за десятерых (В. Распутин: Последний срок); 3) Посидели до глубокой ночи, всё обсудили, выпили чай, разошлись в тишине (Ю. Трифонов: Нетерпение) (последний пример заимствован из работы KRÉKITS 2007: 96).

3.3. Делимитативы в аспекте видовой соотносительности. Как известно, функционально-семантическая категория аспектуальности включает в себя два основных составляющих компонента: 1) вид как «морфологическое ядро», как грамматикализованную и тем самым центральную часть аспектуальности, 2) разные акциональные разряды глаголов, в том числе и способы действия, рассматриваемые в качестве лексико-грамматических группировок (см. БоНДАРКО-БуЛАНИН 1967: 50). Поэтому естественно, что с тех пор как разграничиваются виды (видовые пары) и способы действия, глаголы типа погулять, потанщевать и др. традиционно относят к способам действия, а именно к делимитативному типу. Но нельзя обойти вниманием тот «сдвиг» в аспектологических исследованиях, который можно наблюдать уже начиная с восьмидесятых годов: некоторые лингвисты (см., в частности, Ф. Леманн, Х. Р. Мелиг, М. Ю. Черткова, Е. В. Петрухина, Е. В. Горбова, Анна А. Зализняк и др.) высказываются по этому вопросу на функциональном основании 
в пользу того, чтобы сблизить делимитативы с парными глаголами СВ или даже признать их в качестве парных (а не глаголами perfectiva tantum, как традиционно принято считать). При этом, как правило, они ссылаются на возможность преобразований, предложенных Ю. С. Масловым для подтверждения лексического тождества (прошедшее $\mathrm{CB} \rightarrow$ историческое настоящее или $\mathrm{CB} \rightarrow$ многократное действие НСВ). В своей статье Анна А. Зализняк, И. Л. Микаэлян и А. Д. Шмелев также приравнивают делимитативы к перфективам, соотносительным по виду. Они пишут: «Делимитативы не допускают морфологическую имперфективацию из-за возникающей омонимии с прерывистосмягчительным способом действия (почитыввать). Фактически же функцию имперфективного коррелята к делимитативному глаголу выполняет сам мотивирующий глагол» (ЗАЛИзНяк-МикАЭЛЯн-ШМЕЛЕВ 2010: 16). Сказанное подтверждается смысловым тождеством, сохранившимся в результате следующего преобразования: Он пришел домой, посмотрел новости, почитал газету и лег спать $\rightarrow$ Он приходит домой, смотрит телевизор, читает газету и ложИтся спать (ЗАЛИЗНЯК-МИКАЭЛЯН-ШМЕЛЕВ 2010: 16).

В свете функционального анализа делимитативов не случайно появились новые, более гибкие, видимо, «более осторожные» (менее категоричные) термины, которые не отрицают понимания соотносительности между исходным глаголом и его делимитативным дериватом. Итак, делимитатив - это «видовой способ действия» (термин Х. Р. Мелига) (см. Мелиг 1997: 186) или «видовой партнер» (LEHMANN 1988: 177-178), и он вступает в связь со своим мотивирующим глаголом в качестве «делимитативной пары» или «аспектуальной пары» (cp. аспектуальность и вид) или в качестве «видового партнерства». Выражаясь более традиционно, в рамках педагогической грамматики это должно значить, что отношение типа работать-поработать, cuдетьnосидеть в сущности, хотя с некоторыми оговорками, также следует считать видовой парой. В самом деле, поведение глаголов, объединяемых в корреляцию, убеждает нас в соотносительности. Во-первых, как уже говорилось, 1) тест на настоящее историческое и 2) тест на итерацию, т. е. на преобразование в план многократности являются вескими аргументами в пользу признания противопоставленных глаголов видовой парой: 1) Oн посидел минут пять и ушел $\rightarrow$ Он сидит минут пять и уходит, 2) После обеда она почитала газеты и только потом ушла $\rightarrow$ После обеда она <обычно> читала газеть и только потом уходила. Во-вторых, конечно, реализация НСВ имеет место и в других позициях обязательной имперфективации: почитал - начал (продолжал) читать; надо погулять - не надо (не стоит) гулять и т. д. В-третьих, вопрос о соотносительности может быть рассмотрен и с точки зрения обязательной перфективации. Так, в следующих предложениях делимитатив употребляется в первую очередь потому, что в данном контексте (по разным причинам) просто требуется СВ: Хочется погулять/nосnать; Я хочу с вами поговорить; Как я обещал, я уже поговорил с ним; Садитесь, пожалуйста. Спасибо, я постою. Кроме того, делимитативы часто выступают в такой императивной ситуации, когда предпочтителен именно СВ. Е. В. Петрухина 
отмечает, что в этой позиции они употребляются при выражении вежливого или нейтрального побуждения к действию, причем беспрефиксные глаголы выражали бы категоричность побуждения, ср. Почитай / Читай мне сказку!, Покатай / Катай меня на велосипеде! (Петрухина 2000: 188). В свою очередь, отрицание и в таких контекстах требует НCВ: Не читай сказку!, Не катай меня на велосипеде!

Функциональный анализ делимитативов показывает, что факт отнесенности этих глаголов к определенному способу действия не исключает и не отрицает возможности выступать одновременно и в качестве перфективного коррелята соответствующего беспрефиксного глагола. Однако принятие такого подхода требует его последовательного применения - учета того обстоятельства, что у переходных глаголов, на самом деле, могут быть две разные интерпретации видовой соотносительности: 1) противопоставление при наличии объекта с реализацией результата - это традиционно признаваемая пара (например, читать книгу - прочитать книгу или петь песню - спеть песню) и 2) противопоставление без объекта или с объектом, но без указания на результат: читать-почитать (книгу), петь-попеть (песню) - это «делимитативные видовые пары» (ср. ЗАЛизняк-МикАЭЛян-ШМЕЛЕв 2010: 16). По этому поводу мы разделяем точку зрения Е. В. Горбовой, которая считает, что при расширении видовой соотносительности (при признании делимитативных пар) мультипликатив также должен входить в пару не только с семельфактивом (см. об этом выше в пункте 2.5.), но и с делимитативом, при котором сохраняется мультипликативное значение как первичное значение данного глагола НСВ: прыгать-прыгнуть (через забор) и прыгать-nonpыгать (с полчаса) (см. ГорьовА 2011: 28). На основе изложенного выше, мы пришли к такому убеждению, что при семантической классификации видовых пар на функциональной основе целесообразно выделить и так называемые «делимитативные видовые пары». В таких парах, конечно, исходный глагол НСВ не обнаруживает предельного значения, однако при введении подходящих контекстных ограничителей (часок, полчаса, минут десять и др.) создается ограничение действия «внешним пределом» в имперфективных позициях настоящего исторического и многократности (см. вышеуказанные преобразования).

3.4. О концепции видовых гнезд. Появившийся в последнее время термин «видовое гнездо» («видовой пучок»- англ. aspectual cluster) получил распространение в русской аспектологии вслед за норвежским лингвистом Л. Яндой. Эта концепция изложена в ряде публикаций (например, JANDA 2007, ЯНДА 2012, КУзНЕцОВА-ЯндА 2013). В предлагаемом приближении, аспектуальные корреляции выходят за пределы понятия видовой пары, авторы данного исследовательского коллектива рассматривают все аспектуально значимые дериваты в единстве, с привлечением разных формальных (и тем самым, семантических) модификаций исходного глагола. Таким образом, в рамках данной когнитивной модели в центре внимания стоит не видовая пара как традиционное и ключевое в славянской аспектологии понятие, а предлагается 
термин «видовое гнездо», включающее в себя помимо парного коррелята («естественного перфектива») определенный набор модификаций (в этом плане ср. еще само заглавие статьи Л. Янды и Й. Корбы: «Beyond the pair: Aspectual clusters for learners of Russian», JANDA-KORBA 2008). Авторы различают в русском языке четыре основных типа глаголов CB: 1) естественные перфективы, которые, в сущности, соответствуют перфективам, соотносительным по виду; 2) специализированные перфективы, лексическое значение которых отличается от лексического значения мотивирующего бесприставочного глагола; 3) комплексные перфективы, в которых приставка ограничивает действие, описываемое бесприставочным глаголом. Сюда входят делимитативы, пердуративы, глаголы начинательного и финитивного способов действия. Также отдельный класс составляют 4) однократные перфективы, описывающие единичное действие из ряда повторяющихся (ЯндА 2012: 4).

Нет сомнения, что теория видовых гнезд привлекла к себе внимание в русской аспектологии (см. ГорьовА 2015), но в этой связи данная концепция подверглась и критике (ЗАлизНяк-МикАЭлян 2012). В основе критики Анны А. Зализняк и И. Л. Микаэлян лежит, в частности, тот недостаток модели видовых гнезд, что в рассматриваемой концепции не уделяется достаточного внимания функциональному критерию Ю. С. Маслова, т. е. достоверно применяемые тесты касательно выделения приставочной видовой пары (в терминологии Янды: касательно определения естественного перфектива) оставлены без внимания. Это значит, что отграничение естественных перфективов от прочих модификаций делается без каких-либо объективных критериев. Авторы считают, что описание коррелятивности в форме «пучков» («кластеров») как бы отменяет понятие видовой пары как конституирующей категории русской аспектУальной системЫ (ЗАЛИЗНЯК-МИКАЭЛЯН-ШМЕЛЕВ 2010: 11).

Нам представляется, что модель видовых гнезд как система глагольных классификаторов имеет неоценимое достоинство в педагогическом плане для иностранной аудитории, при сопоставительном изучении русских глагольных модификаций и их эквивалентов в неславянских языках. Не случайно попытки описания глаголов в единстве их лексико-акциональных функций были сделаны и в аспектологических исследованиях полонистики: см. разработки многочисленных глагольно-словообразовательных гнезд (в сущности, аспектуальных гнезд/кластеров) в качестве лексикографической трактовки корреляций на корпусе польского языка с привлечением немецких эквивалентов (COCKIEWICZ 1992), английских эквивалентов (COCKIEWICZ-MATLAK 1995) и венгерских эквивалентов (РА́trovics 2011).

\section{Литература}

АПРЕСЯН 1997 = АПРЕСян Ю. Д. (ред.) Новый объяснительный словарь синонимов русского языка. Вып. 1. Москва: «Языки русской культуры», 1997.

БондАРКО 1986 = БондАРКО А. В. Семантика предела. Вопросы языкознания 1986/1: $14-25$. 
БОНДАРКО-БУЛАНИН 1967 = БОНДАРКО А. В., БуЛАНИН Л. Л. Русский глагол. Ленинград: «Просвещение», 1967.

ГЛОВИНСКАЯ 1982 = ГЛОВИНСКАЯ М. Я. Семантические типы видовых противопоставлений русского глагола. Москва: «Наука», 1982.

ГОРБОВА 2010 = ГОРБОВА Е. В. Акииональность глагольной лексики и аспектуальные граммемы. Вопросы взаимодействия. Санкт-Петербург: «Санкт-Петербургский государственный университет», 2010.

ГорБОВА 2011 = ГорьОВА Е. В. Видовая парность русского глагола: проблемы и решения. Вопросы языкознания 2011/4: 20-45.

ГОРБОВА 2015 = ГОРБОВА Е. В. Видообразование русского глагола: префиксация и / или суффиксация? Вопросы языкознания 2015/1: 7-38.

ЗАЛИЗНЯК-МИКАЭЛЯн 2012 = ЗАЛИЗНЯк Анна А., МиКАЭЛЯн И. Л. О некоторых дискуссионных моментах аспектологической концепции Лоры Янды. Bonpocbl языкознания 2012/6: 48-65.

ЗАЛИЗНЯК-МИКАЭЛЯН-ШМЕЛЕВ 2010 = ЗАЛИЗНЯк Анна А., МИКАЭЛЯН И. Л., ШМЕЛЕВ А. Д. Видовая коррелятивность в русском языке: в защиту видовой пары. Bопросы языкознания 2010/1: 3-23.

ЗАЛИЗНЯК-ШМЕЛЕВ 2000 = ЗАЛИЗНЯк Анна А., ШМЕЛЕВ А. Д. Ведение в русскую аспектологию. Москва: «Языки русской культуры». 2000.

КРЕКИЧ 1989 = КРЕКИЧ Й. Семантика и прагматика временно-предельных глаголов. Budapest: Tankönyvkiadó, 1989.

КУЗНЕЦОВА-ЯНДА 2013 = КУЗНЕЦОВА Ю. Л., ЯНДА Л. А. ПриставКИ в свете когнИтивной лингвистики и типологии (отклик на статью А. А. Зализняк и И. Л. Микаэлян), Вопросы языкознания 2013/4: 87-96.

МАСЛов 1948 = МАСЛов Ю. С. Вид и лексическое значение глагола в современном русском литературном языке. Известия АН СССР. Отделение литературы и языка. Т. 7. Вып. 4. Москва, 1948. 303-316.

МЕлиГ 1997 = МЕлиГ Х. Р. Ответы на вопросы анкеты аспектологического семинара филологического факультета МГУ. В кн.: Труды аспектологического семинара филологического факультета МГУ. Т. 2. Москва: «Издательство Московского университета», 1997. 183-186.

ПАДУЧЕВА 1996 = ПАДУЧЕВА Е. В. Семантические исследования. Семантика времени и вида в русском языке. Семантика нарратива. Москва: «Языки славянской культуры», 1996.

ПЕтрУХИНА 2000 = ПЕтрухинА Е. В. Аспектуальнье категории глагола в русском языке (в сопоставлении с чешским, словачким, польским и болгарским языками). Москва: «Издательство Московского университета», 2000.

ХРАКОВСКИЙ 1997 = ХРАКОВСКИЙ В. С. МультиПликативы и семельфактивы (проблема видовой пары). В кн.: КАРоляк С. (ред.) Семантика и структура славянского вида 2. Kraków: WSP, 1997. 227-239.

ЯндА 2012 = ЯНдА Л. А. Русские приставки как система глагольных классификаторов. Вопросы языкознания 2012/6: 3-47.

ЯСАИ 2013 = ЯСАИ Л. Видовая пара и ее разные трактовки. Studia Slavica Hung. 58 (2013): 377-385.

COCKIEWICZ 1992 = COCKIEWICZ W. Aspekt na tle systemu stowotwórczego polskiego czasownika i jego funkcyjne odpowiedniki w języku niemieckim. (Rozprawy habilitacyjne 231.) Kraków: Uniwersytet Jagielloński, 1992. 
CockiewicZ-MATLAK 1995 = CocKIEWICZ W., MATLAK A. Strukturalny stownik aspektowy czasowników polskich. Kraków: Uniwersytet Jagielloński, 1995.

JANDA 2007 = JANDA L. Aspectual clusters of Russian verb. Studies in Language 31 (2007): 607-648.

JANDA-KORBA 2008 = JANDA L., KORBA J. Beyond the pair. Aspectual clusters for learners of Russian. Slavic and East European Journal 52 (2008): 254-270.

KRÉKITS 2007 = KRÉKITS J. Zur Diskussion über die delimitativen und perdurativen Verben. Dissertationes Slavicae. Sectio Linguistica XXVII. Szeged, 2007. 93-99.

LEHMANN 1988 = LEHMANN V. Der russische Aspekt und die lexikalische Bedeutung des Verbs. Zeitschrift für slavische Philologie 48 (1988): 170-181.

PÁtROVICS 2011 = PÁTROVICs Péter: A lengyel igeaspektus kérdései. Lengyel-magyar strukturális aspektusszótár. Habilitációs értekezés. Budapest: ELTE BTK, 2011. 